\title{
The Activation and Restoration of Shame in an Intimate Relationship: A First-Hand Account of Self-Injury
}

\author{
Nina Veetnisha Gunnarsson \\ University of Jönköping, Sweden
}

DOI: http://dx.doi.org/10.18778/1733-8077.17.2.06

Keywords:

Self-Injury; Shame; Social Bonds; Critical Other; First-Person Account

\begin{abstract}
This paper is grounded in a first-hand account of my own experiences with self-injury and shame. By using my personal diary entries as support for this account and a sociological framework of shame, I explore the process of shame and shame reactions in an intimate relationship. I illustrate how shame was activated by my internalized critical other, how the shame cycle de-stabilized my relationship, and, finally, how shame was restored through the other's validation and acceptance, or how it led to more shame managed by self-injury. However, this account is not simply about self-analysis, or a need to indulge in my pain; rather, it is an inner dialogue that rests on the commitment to develop a richer understanding of the personal and interpersonal experiences of self-injury and shame. Today, I finally understand how shame works and this has helped me to not get caught up in my emotions. So, although shame may take a hold of me at times, I am no longer, like before, controlled by my shame.
\end{abstract}

Nina Veetnisha Gunnarsson is an Assistant Professor at the University of Jönköping, School of Health and Welfare, Department of Social Work, Sweden. Her research interest focuses on self-injury, particularly its connection with shame and social interaction. She has previously published two articles on self-injury: "The Self-Perpetuating Cycle of Shame and Self-Injury" and "The Scarred Body: A Personal Reflection of Self-Injury Scars."

email address: Nina.Gunnarsson@ju.se

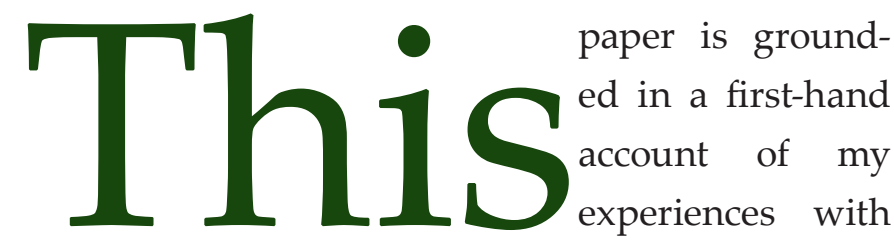

self-injury and shame. By using my personal diary entries as support for this account and a sociological framework of shame (e.g., Scheff, Lewis, and Retzinger), I explore the process of shame and shame reactions in an intimate relationship. I wrote the diary entries in proximity to the actual events and self-injury activities, sometimes in the moment of despair 
and shame, sometimes in a more distanced moment (hours or occasionally days later). However, I did not keep a diary to have it published, and it was not intended as a record of a researcher's experiences of shame and self-injury. The diary, however, provides written interpretive material that allows me to look at how shame disrupts a relationship and threatens the connection between the self and the other. Although the diary is about past experiences, I still embody similar experiences. Also, I can never observe the unmediated "II" as Ellis (1991:29) put it, because "reflection changes it to a past "me."

I have tried for many years to understand shame in myself and to make sense of my unbearable emotional pain, and my behaviors because of that "pain," to be able to live a life I consider to be ordinary and good enough. However, this account is not simply about self-analysis, or a need to indulge in my pain; rather, it is an inner dialogue that is supported by shared significant symbols of emotions and identity that allow for new insights to extend sociological understanding (Sparkes 2000). Using the self as a source of data has been criticized for being self-indulgent, narcissistic, introspective, and individualized (Holt 2003; Atkinson 2006). However, such criticisms, according to Mykhalovskiy (1996), are misguided, as the individual and the social are not two separate things. On the contrary, "writing about the self involves, at the same time, writing about the 'other' and how work on the 'other' is also about the self of the writer" (Mykhalovskiy 1996:133).

Self-injury is a strategy used to manage unbearable emotional pain. It involves acts of cutting or burning one's skin, pin sticking, interfering with wound healing, and smashing one's hand or foot bones (Adler and Adler 2011; Favazza 2011). It is about in- ternal pain that is manifested in external injuries, wounds, and scars. Although self-injury is a highly privatized act, carried out outside of others' views and often kept hidden from others, it is nevertheless a highly social practice that needs to be understood and explored as an interactive and cultural practice/ phenomenon (Adler and Adler 2011; Steggals 2015; Brossard 2018).

In a previous theoretical publication (Gunnarsson 2020), I argued that shame is significant for understanding self-injury and that self-injury is performed as a response to shame, to mitigate it. By fending off shame through self-injury, the individual can (temporarily) uphold social and cultural commitments and maintain social bonds with others. He or she can thus control the self and go on with everyday life (Brossard 2018). However, because self-injury is a stigmatized practice (Long 2018), it tends to lead to more shame, thus disrupting the social order (Gunnarsson 2020). In this firsthand account, I illustrate how shame was activated by my internalized critical other, how the shame cycle de-stabilized my relationship, and, finally, how shame was restored through the other's validation and acceptance, or how it led to more shame managed by self-injury.

\section{A Sociological Framework of Shame}

Emotionality relates to the self, but also relationships, thus, to social connections and social bonds. Denzin (1983:404) defines emotions as: "temporally embodied self-feelings which arise from emotional social acts persons direct to self or have directed toward them by others." How we view the self and act is heavily dependent on what we believe the other(s) think of us (Cooley 1902; Lundgren 2004). Some emotions, like shame, are more social than others 
(Scheff 2003), but all emotions are directed at the self and the other (Scheff 2000).

Scheff $(2000 ; 2014)$ considers shame to be a repressed emotion in the western world. An individual may thus have a hard time acknowledging experiences of shame, and it tends to be hidden in interactions and relationships. Shame can be viewed as a family of emotions that range from an "ordinary" shame, that is, mild embarrassment and social discomfort, to a more intense and penetrating shame, which Scheff and Retzinger (2000) describe as pathological. This latter kind of shame is known to be experienced by individuals with emotional and mental difficulties or illnesses (e.g., Retzinger 2002).

Scheff (2014) defines shame as a self-other feeling that is generated when there is a threat to the social bond. He draws on the works of Cooley's looking glass self, Elias' civilization thesis, and Lewis' shame theory, thus presenting an account of the role of shame in social life. Lewis (1971) acknowledges that relationships move through interludes of connection, disconnection, and reconnection, although when one feels shame, disconnection is at the forefront of one's self-other relationship. In shame, one may either question whether one is worthy of connection or one may feel utterly unworthy of connection. Shame thus involves an awareness of others' regard for oneself; it involves always having an audience, real or imagined, specific or generalized. This audience can be internalized, because we can feel shame even when we are alone, hence "in response to actions in the inner theater, in the interior monologue in which we see ourselves from the point of view of others" (Scheff 2000:95). Shame, therefore, reflects our concerns with how we are perceived by others and arises as we take the role of the other.
Experiences of shame can include being scorned, ridiculed, belittled, ostracized, or demeaned, and may disrupt relationships with others; it causes potential disconnections between the self and others. There are hundreds of different code words for shame, which are used to label shame without calling it by name (see: Retzinger 1995). Retzinger (1995; 2002) presents a list of such cue words for shame, which may be verbal cues of separation, isolation, ridicule, foolishness, and inadequacies, or verbal hiding behaviors that can serve to distance a feeling from the self or affirm a bond with others. Both verbal and non-verbal cues often come in combination and are triggered in certain contexts, that is, it is the position of the self in relation with the other, the situation, and the verbal statements used by different parties that determine whether or not shame is experienced.

In shame, the position of the self in relation to the other is connected with an imbalance in the relationships, and "the self is always perceived to be in the inferior position" (Scheff and Retzinger 2000:66). Shame also entails alienation from others and reveals the extent to which individuals are attuned to each other. When social bonds are secure, individuals feel connected with others and experience pride and solidarity. In shame, the social bond is insecure or in some way threatened (Scheff 2003). Scheff (2001:216) understands an insecure bond as a relationship that lacks a "history containing moments of mutual understanding (both cognitive and emotional)" or a relationship that entails low levels of equality. Scheff also pinpoints that shame is not solely negative, but signals to people a need to manage the threat to the bond.

Shame and anger often concur (Lewis 1971), and an individual experiencing shame wants to hide from 
the hurt, which means anger can be turned against the self or be pushed outwards, towards the other. Hence, there is an escalating alternation between shame and anger in interactions and relationships (Retzinger 1995). When ignoring the shame, identification with the other also becomes difficult. Retzinger (1991:39) notes that "the other person is then experienced as the source of the hurt."

To summarize, shame is not triggered in isolation within the individual self, but derives from how one believes one appears to others. It is activated whenever there is a threat to the social bond, whether this constitutes a real threat or an imagined one. For shame to be repaired, one needs to acknowledge and communicate its presence (Lewis 1971; Lynd 2013) or change other people's judgments (Leeming and Boyle 2013). It is when others can accept and validate a person that a person's shame is likely to lessen. When shame is acknowledged, it is often a brief experience in everyday life; moreover, it allows the social bond to be repaired (Scheff and Retzinger 2000). Open expressions of shame can then lead to negotiation, compromise, and problem-solving. This means expressing one's shame is a functional means of lessening shame. However, if individuals do not know that it is shame they experience, it becomes impossible to negotiate and solve problems within interactions and relationships, hence leading to alienation and risk for suicide, self-injury, and mental illnesses (Retzinger 2002; Gunnarsson 2020).

\section{Shame and Self-Injury}

Shame figures frequently in literature, research, and individuals' experiences about self-injury (Steggals 2015; Gunnarsson 2020). For example, shame in self-injury may be bound with self-persecution, self-punishment, self-blame, and experiencing that one is a "fundamental failure of human being" (Steggals 2015:167). Furthermore, it may be expressed in terms of different cue words such as "self-loathing" (Solomon and Farrand 1996), a sense of "failed self" (McDermott, Roen, and Scourfield 2008), "selfdoubt," "self-disgust" (Rao 2006), "humiliation and aggression against the self" (Le Breton 2018), as "negative self-evaluations" (Huey, Hryniewicz, and Fthenos 2014), or thinking one "deserves to be punished" (Hill and Dallos 2011; Steggals 2015).

Moreover, shame is often studied as self-hatred, low self-esteem, self-punishment, and self-dissatisfaction (e.g., Ivanhoff, Linehan, and Brown 2001; Gilbert et al. 2010; Victor and Klonsky 2014). Ivanhoff, Linehan, and Brown (2001) highlighted that no other emotions, but shame could predict the increase in urges to self-injure. The existence of high levels of shame before starting therapy increased the odds of self-injury within the first four months of therapy (Ivanhoff et al. 2001). Xavier, Pinto-Gouveia, and Cunha (2016:583) found how self-criticism in the form of self-hatred was strongly associated with self-injury and those with "persecutory and hatred self-attacking" were most likely to engage in self-injury. Schoenleber, Berenbaum, and Motl (2014) disclosed how proneness to shame was associated with more frequent bouts of self-injury, which, in turn, could reduce the individual's feelings of shame. Self-injury, thus, worked as shame management to lessen shame. Other studies have shown how self-injury and suicide are used to avoid or escape shame (Fullagar 2003; McDermott et al. 2008); furthermore, McDermott and colleagues (2008) emphasized how shame was an unspoken emotion in self-injury.

My experience of shame was not the "ordinary" mild and quickly resolved shame or embarrassment that everyone experiences from time to time, which 
Goffman (1967) found is almost always present in everyday face-to-face interactions. Rather, it was the kind of a shame that overrides and engulfs the entire self (Scheff 2000), a penetrating and intense form of shame, which may be said to be pathological in its intensity and prolonged duration. It has "stayed with" me for many years, almost becoming part of my self-image and identity (Scheff and Retzinger 2000). Such shame, when it is outwardly manifested, is extremely painful and damaging especially for the individual self, but also in terms of relationships, interactions, and connections with others (Lewis 1971; Scheff 2000).

\section{An Autobiographical Note}

The self-injury started in my adult years (at approximately 35 years of age), after having attended my first drug and alcohol treatment. Although I was self-destructive (e.g., binge drinking, drug abuse, reckless behavior) from my teens and during different periods of my life, the skin cutting was never repetitive until later in my life (Favazza 2011). This first-hand account particularly focuses on an intense period over five years when I repeatedly injured my body, by cutting and burning myself. At the time, I was a Ph.D. student and a single mother. I was also involved in an intimate heterosexual relationship, which I ended after approximately two years. The termination of the relationship was a response to my realization that I could not continue because of all the different self-destructive feelings and behaviors. The reason was that shame was intensely and repeatedly triggered in my intimate relationship.

At the time of writing in my diary, I did not know much about shame. Although I was attending intensive therapy, we seldom spoke about shame.
Over the years, I read a vast number of studies and publications about self-injury and shame. Eventually, I also started to talk about shame in therapy. It was then that I gradually came to comprehend how shame affected my own experiences of the self and my connection with the other (e.g., my partner). I also began to ponder more seriously about shame as a possible core emotion in self-injury, and the possibility that it could explicate the seemingly inexplicable act of physically injuring one's body. This resulted later on in an article that explored shame as an explanation to why individuals physically hurt themselves (Gunnarsson 2020).

A fair amount of time has passed since those approximately five years with on and off self-injury. Nonetheless, I have also had numerous periods of self-injury since then. Regardless of whether or not I engage in self-injurious behaviors, I always have an embodied "skin-cutter membership," as materialized through the scars on my body, most of which reside vividly on my arms. In the eyes of others, I will always be a potential skin-cutter, or the very least a former one. My belonging to the potential skin-cutter category, therefore, is a lifelong and non-negotiable membership. Although most scars have faded into white marks, they can hardly be missed or mistaken for what "they are."

\section{To Make Use of the Personal}

Personal experiences are said to offer new insights by drawing on personalized accounts from the author/researcher and to extend sociological understanding (Sparkes 2000). There are different approaches to writing the personal, that is, where the researcher's experiences are described and analyzed, and where the voice of the researcher is present in the text. There is the sociological introspection 
(Ellis 1991), autobiography (Mykhalovskiy 1996), first-person accounts (Rier 2000), and autoethnography (Anderson 2006; Ellis, Adams, and Bochner 2011), to mention a few. In autobiography, the author retroactively writes about past experiences, while in ethnography, the researcher becomes somehow engaged as a participant-observer in the culture (Ellis, Adams, and Bochner 2011). Autoethnography, according to Ellis, Adam, and Bochner (2011:277), is a combination of the two, where one seeks to "produce aesthetic and evocative thick descriptions of personal and interpersonal experiences." Here, I draw on first-hand accounts of my own experience of shame and self-injury. It is not autoethnography as such, but has elements of an autobiography that makes use of personal diary excerpts and rests on the commitment of developing a richer understanding of the personal and interpersonal experiences of self-injury and shame. The focus on shame came about after exploring the issue theoretically in a previous article and also because I knew from experience that my shame was particularly triggered in intimate relationships and interactions.

For Mykhalovskiy (1996), the personal is always social; and to write individual experiences is to write social experiences. As individuals, we do not accumulate experiences in a social vacuum; therefore, it is always an intersubjective attempt to write the personal. To write myself into my work means that I experience and present the phenomenon of self-injury and shame simultaneously as both subjective/ personal and objective/public (Church 1995). As Church (1995:5) argues:

I assume that my subjectivity is filled with the voices of other people...Writing about myself is a way of writing about these others and about the worlds which we create/inhabit...Because my subjective ex- perience is part of the world, the story which emerges is not completely private and idiosyncratic.

This means that I am part of the cultural context from which I experience myself, others, and our jointly shared world. If my perspective cannot speak of more general and social experiences, how then can any narrative and story from the other(s) be culturally relevant (Sparkes 2000)?

There are some important reasons as to why it is significant and informative to use personal accounts and introspections in making sense of self-injury and shame. First, since people often are poor subjects when it comes to making witness about their emotions, especially shame (Scheff 2003), personal accounts can make it possible to come closer to a deeper and fuller understanding of emotions and emotional states involved, before one makes the "decision" to cut. This may be especially important in terms of shame experiences, as they are often repressed or hidden from the self and others (Lewis 1971; Scheff 2003). Second, self-injury is a stigmatized practice and something people carry out privately and in secret, and the self-injurer's experiences are often intertwined with professional and medical discourses that find self-injury to be pathological (Favazza 2011; Long 2018). Hence, drawing on my experiences with shame and self-injury and retrospective journal accounts written in close proximity to the accounted for events, there is an advantage that I can "speak about the unspeakable" and disclose experiences otherwise forgotten or hidden.

\section{Ethical Issues}

This article draws on personal diary excerpts that show what happens in an intimate relationship 
when shame is involved. There is an actual person besides myself that figures in the diary extracts, who has not consented to appear in the study. Thus, I have carefully omitted any details about the person in question, and although there are occasional paraphrased dialogues in the examples, it has no discerning content.

Another ethical issue is about the amount of personal disclosure and how much of myself I put out there. This ethical issue also pertains to the scientific objective, and hence agreeing with the criticism that writing about the self needs some level of abstraction and/or connection with theory and literature (Atkinson 1997; Wall 2016). Moreover, an ethical position is not just about asking oneself if one is "saying too much" (Wall 2016), it is also about not forcing too much of my emotions and experiences on others, namely, people who have not asked for my personal disclosures. Here, I have tried to balance this by not exposing everything about myself and my life, but instead focusing on a few happenings.

\section{The Personal Text Materials}

The personal texts and discourses that comprise my diary, written between 2004 and 2015, are used as empirical data. The diary encompasses 128 pages and 46,858 words. In particular, the diary entries from 2005 until 2008 are analyzed more thoroughly, covering forty-eight pages, including 16,317 words. The entries in my diary were written in Swedish and were translated by an English/Swedish-speaking language editor and myself. The entire diary covers events, accounts, thoughts, and emotions, specifically relating to intimate relationships. The present study uses diary entries concerning a specific relationship, and these were the extracts chosen for the analysis. It was during this time that I frequently engaged in episodes of self-injury. The contents of the diary were analyzed by looking for verbal and non-verbal clues of shame, according to Retzinger's (1995) list. I considered the position of myself in relation to the other (my partner) and the verbal statements exchanged between us, and how the specific situation could be indicative of shame experiences. Besides my personal accounts, the study also draws on the accounts and experiences of other self-injuring individuals, for example, in previously published self-injury autobiographies (e.g., Kettlewell 1999; Smith 2006) and research publications (e.g., Harris 2000; Rao 2006).

Although I am not presently injuring myself repetitively, there is no distinct line between the past and the present or of what may happen in the future. The trajectory of self-injury continues, and I cannot say that it was then and there and that I have now overcome the urges to cut my skin. While the diary entries are retrospective, I also have memories, embodied emotions, and bodily sensations of these times that linger in my body/mind. Moreover, the past is always felt, understood, and rewritten from the present, and this first-hand account is an attempt to make sense of a specific social and cultural phenomenon by re-experiencing it. By doing so, I also create the conditions for my own experiences and choose what parts should be in focus. In my diary, I have written about other subjects and aspects of the relationship and self-injury. Nonetheless, in this account, the focus has been on reflections on how shame can be activated and restored in an intimate relationship.

My diary contains reflections and accounts that explain my own and the other's behavior, for example, how my seemingly unacceptable behaviors were excused and justified (Scott and Lyman 1968) and 
accompanied with shame and shame reactions. In previous literature and theories about shame, this account addresses what triggered my shame, and how shame worked through the self-other relationship. Moreover, it also addresses how shame not only initiated self-injury, but also how self-injury was used to manage shame states/reactions by restoring the connection with the self and the other (Gunnarsson 2020).

Scott and Lyman (1968:47) have suggested that people construct social meanings through accounts, which they see as likely being invoked when "a person is accused of having done something bad, wrong, inept, unwelcome"-hence untoward. Although Lyman and Scott do not mention it, justifying accounts may also include what a person may think she/he has done wrong, with no wrongdoing necessarily being done. Considering the self-conscious nature of shame, justifying accounts are likely to occur in response to one's critical other and will, most likely, also involve emotions, such as shame. The emotional aspect, however, is omitted from Scott and Lyman's accounts. They (Scott and Lyman 1968:46) define an account as "a linguistic device used whenever an action is subjected to evaluative inquiry, or a statement made by people to explain unanticipated or untoward behavior." Furthermore, accounts may or may not be honored, that is, they can be respected by the other (Scott and Lyman 1968). When an account is honored, it is viewed as effective in restoring stability in a relationship, for successfully having re-established social and interactional order. Hence, one would assume that shame is also reduced when an account is honored.

Below, I recount those instances in my diary when shame was activated, often through the view of the critical internalized other. I also address how shame generated more shame in the self-other relationship, leading to a cycle of shame, which only grew more intense in each judgment that was bestowed in the interactions. Finally, it was through the other's validation and justification of the self, which mended my self-image that made it possible for me to reconnect with my partner again. As it was not always possible to be validated by the other, self-injury became a way to validate myself, or a way to restore shame and myself, to be able to go on with my life and interact with others and fulfill my different social and cultural commitments (Gunnarsson 2020).

\section{The Critical Internalized Other}

In my diary, the activation of shame is always connected with how the other viewed me or the imagination and anticipation of the other's view, and as evaluated in my inner theater of seeing the self through the other's eyes (Scheff 2000). Shame is related with the other, how I assume I appear to him, which I interpret as me embodying an internalized critical other (Lewis 1971). As humans, we are an object to ourselves (Mead 1934), meaning we can perceive ourselves, have conceptions of who we are, and communicate and act towards ourselves. This self-interaction is the basis for social interaction, that is, how we interpret and respond to others is embedded in how we view ourselves. Moreover, to view the self as one thinks the other would, and be judged accordingly, is about internalizing that view per se as being the self, that is, I am the person whom I think the other sees me as. The potential judgment of others is a reality whenever one merely imagines or assumes the self-negativity, and as Cooley (1902) put it, to be imagined is to be socially real.

In the first example from the diary extract below, I realize that the unworthiness, the shame I am feel- 
ing, is not only about the current situation, but also stems from experiences in the past. It is about past insecurities or threatened bonds that make themselves known in the present.

\section{Example 1}

At the moment, I am dazzled by my own shame, guilt, and fear. Traumatized by my past; you are a part of it and the now escapes in my spasm. You disappear from my conscious sphere, and I retreat into my own dark soul, filled with bitter memories that not even I know about. Afterwards, I understand that you have had to give up on yourself, so I may exist. And it comes as a letter in the mail. Shame follows the actions of my way. I crawl into a corner to escape my imagined executioner. Your irritation and powerlessness are my punishment. [The diary, Monday morning, November 13, 2005 p. 35]

I write openly about shame, but other cue words are also used, such as retreating, as well as paralinguistic cue words such as "crawl into a corner to escape," which is a visual response to shame (Retzinger 2002). I believed I needed to be punished for being the person I presumed he saw in me. His irritation (anger) thus makes him frustrated with me; consequently, I feel rejected by him. As shame also signals a potential threat to survival (Scheff 2003), it also triggers the infant's experience in me. My partner becomes in that moment my "imagined executor." Here, I have a hard time identifying with him and he becomes someone who might hurt me. This is because, in shame, the hurt can be felt like it is coming from the outside, from the other (Retzinger 1991). Still, I realize now when writing this that it was and is all in my mind; he is an imaginary perpetrator or someone from the past. My emotional response here depends on contextual cues, whereas I react to how I perceive the situation in the moment of shame. My reactions are internal, but manifested externally and acted upon by past, historical memories of threatened or broken social bonds.

In example 2, my shame awakens due to an incident that happened the day before. I wake up with shame, as I remember what had transpired the day before. My outburst of jealousy and anxiety/despair for thinking he had cheated on me. The example continues to describe what happened in our conversation in the morning, over the telephone. I talked to my partner, and at first, his voice soothes me. It is, however, a "brief peace" because his voice is distant and judgmental, and he scolds me for the jealousy I had displayed the day before (being jealous may also be a sign of shame). Even today, I can recall his irritation, his voice being distant and full of contempt. Here, our bond is clearly threatened by my display of jealousy, but I try to mend the bond by explaining why I had drawn such conclusions. However, at the moment he cannot honor my accounts (Scott and Lyman 1968). So, my shame just spirals away, and I am caught in a state of self-hatred. This relentless hatred is a clear sign of how my entire self, the general self (Turner 2006), is involved in this overt shame experience (Lewis 1971), which is displayed in the diary entry. In overt shame, emotions are felt intensely, but may be mislabeled by, for example, self-hatred.

\section{Example 2}

I awaken and feel ashamed. I remember yesterday and my behavior, my jealousy, and anxiety. I can look at what happened a little through your eyes, with my common sense intact. Having a healthy human being's mental images. I also understand that nothing has happened and that you have not at all fooled around or cheated on me. A brief moment of peace because your voice and your distancing, as well as 
your feelings, make my shame awaken. Despair takes a grip on me when you say my expressions of jealousy are not okay. As if I do not know it, as if I am not already two steps ahead of you and hate myself, unrelentingly. I know that that is not what you want, for me to hate myself, but how can I not?

I try to explain how my thoughts and feelings at that moment are real, how there is nothing else, until now in the morning. My common sense is blown away in the affective storm. But, there are no explanations that give me peace; no explanation can erase your feelings and your powerlessness. [The diary, Saturday, January 14, 2006, pp. 46-47]

It is clear that my guilt, when enmeshed with shame, cannot easily be discharged by a simple apology. I do not even try to apologize because I am caught in a cycle of trying to justify my behavior. Not to excuse it (because I know very well I was wrong), but to explain what had led me to draw the conclusions that I did and how "my thoughts and feelings at that moment are real, how there is nothing else." In my account, I try to create social meaning by drawing on the past and the present (Scott and Lyman 1968). I write that at that moment, my common sense "is blown away in the affective storm." I am left within the storm of my affects; I am caught in my shame and the shame cycle (Gunnarsson 2020). Shame is activated through how I see myself in him, and I know that I am righteously to blame for how he sees me and for what happens between us. The cycle of shame is a reaction to him not wanting to hear my explanations, and I am stuck in experiences of self-contempt that I cannot get rid of on my own. Shame is known to trigger more shame in what Scheff (2000) calls a triple shame loop, that is, being ashamed, being ashamed of being ashamed, and being ashamed of causing further shame in others.
Throughout the diary, the self-blame is recurrent (see also: Long 2018), and there is no criticism on my part about his actions and words towards me. He simply cannot, in my eyes, do anything wrong. I am the one to blame for all the problems in our relationship, for what happens between us, and also for what happens in him. My self-worth may be related to what Bartky (1990) considers determined by women's status in the social hierarchy. However, I also internalize the societal ideals, which contribute to the inferiority that I experienced in the relationship (Seu 2006). I position myself as being beneath him, and this intrinsically informs my shame. I think that I am to blame for what goes on in our relationships. I contribute as such to my inferiority, to the "perpetuation of women's position," as Seu (2006:289) puts it.

\section{The Shame Cycle}

The excerpt in example 2 above continues below in example 3. In this extract, the cycle of shame becomes clear, that is, how shame turns into more and more shame (Scheff 2000; Gunnarsson 2020). When taking the perspective of the other (Mead 1934), it can cause a cycle of shame and self-injury that can arise in seemingly trivial situations and ordinary interactions and become self-perpetuating (Gunnarsson 2020).

Below, I try to explain my predicament, but my partner does not allow me to get away with it. I blamed him, and he is mad at me for not taking responsibility for my actions and my words. What I am doing in this account is what Scott and Lyman (1968) call accounts of scapegoating. It is a type of excuse for an untoward behavior that calls the other into question. I allege in the example below that my behavior is a response to his behavior (i.e., 
that of not calling or texting me). Guilt and shame are likely to follow both before and after excuses and justifications have been made. What is especially significant here is the fact that my excuse is not honored because, in my partner's mind, the excuse is unreasonable (Scott and Lyman 1968). He sees right through my scapegoating and refuses to "take on the blame," and this turns into another shaming situation for me. I am ashamed again upon being accused of blaming him; he quickly redirects the blame back to me, and shame is "at its rightful owner."

\section{Example 3}

I cannot fix what is happening, but must accept what you are saying and feeling. If only you could have called, if only you could have sent me a text message, I try to say. You don't accept it. Don't put the blame on me, you say, and my self-contempt tries to find its way out. I put my shit on you; you push it back and I accept it, gratefully. The burden grows and the guilt and the shame are at its rightful owner. But, I don't want it either, so stop! You don't accept my projections and I must carry them myself-all these hard feelings that I'll do anything to get rid of.

My feelings alternate during our conversation, from a growing, intense panic to an absent-minded resignation. I am ashamed of what I say and do. I am ashamed of needing to explain myself to you and making excuses for my behaviors. I am ashamed of who I am. And I am ashamed of not being able to love myself. [The diary, Saturday, January 14, 2006, pp. 47, 49]

When he does not accept my projections, this makes my shame even more intense. The shame intensifies, and it becomes more and more unbearable for each word exchanged between him and me. I feel ashamed of everything I do and say, and for what I cannot do (e.g., love myself). It is socially and culturally expected that an adult loves oneself, or at least accepts the self. There is a vast amount of self-help books and professional literature about self-esteem and shame, stating how one supposedly needs to learn to love oneself before being able to love someone else. Hooks (2000), for example, proposes that self-acceptance and self-love are necessary to have a sound relationship. I experienced myself as a failure, for not living up to the social and cultural values and ideas of intimate, adult love. I remember how belittled I felt in these moments when I could not get a grip of myself. The progression of shame may also mean that one feels inferior in relation to the other (Scheff and Retzinger 2000). I experienced the relationship as unequal; his opinions and attitudes were often influencing my thoughts and feelings about myself. I felt I was nothing without him. But, I was also nothing with him. This discrepancy was my everyday companion, and I did not know how to retract the shame I felt for being lesser than him.

\section{The Validation and Justification from the Other}

If shame is triggered in interactions and relationships with a critical real or imagined other, this means that there is a need for a repositioning of the self in relation to others (Leeming and Boyle 2013). According to Leeming and Boyle (2013), the most important factor in repairing shame is changing the judgments of others. Thus, when others could once again accept and validate the person, then shame was likely to lessen, which is some sort of forgiveness, or validation of one's behavior, intentions, or self-worth from someone. 
In example 4 (a continuing entry from example 1), the assurance from my partner that he is not going to leave me is what lessens my shame: "I let go of my weight and [my] tears wet your shoulder." When I feel that his love returns and that hope for a future together seems possible again, I write, "at that moment, I am again a woman that is worthy to be loved."

\section{Example 4}

In the morning, we talk; I love you for that. You know what I am thinking and assure me that you will not leave me. I let go of my weight and tears wet your shoulder. Love returns in your eyes, happiness seeks me in my yearning, and hope puts us back together again. Hope that a future might still be possible, side by side with the illness of fear. At that moment, I am once again a woman, worthy of being loved. [The diary, Monday, November 13, 2005, p. 35]

The above example shows how shame is repaired with the other's ability to lessen my shame by validating my experiences and me. Here, it rests upon his reassurance that he will not leave me. Hence, the social bond is for the moment intact or secured, and the feeling of abandonment temporarily vanishes. This is because the love returns in his eyes, and I feel justified again for being a woman who can be loved and is worthy of that love. Shame goes away when I can reconnect with him and feel connected again, and the social bond is, at least temporarily, mended and our relationship is back to where I do not feel inferior to him. On the other hand, as I am dependent on how I look in his eyes, to reduce my shame, I also need to constantly monitor myself to know what he expects of me and my behavior, which may further drive feelings of shame.

When an account is honored, it means that it was effective, and that "equilibrium" is restored in a relationship (Scott and Lyman 1968). If shame is triggered in interactions when one feels unworthy, incompetent, unlovable, or simply failed, or in any other way feeling rejected, ridiculed, or told off, then shame will follow in the footsteps of many excuses and justifying accounts. When an account is honored, shame is likely to be less intense or perhaps even dissipate. When considering that shame may be a significant emotion that accompanies the accounts given to explain untoward behavior, the act of honoring the excuses and justifications is similar to that of being validated by the other.

\section{The Restoration of the Self through Self- Injury}

When situations were such that no validation, forgiveness, or repair of my shame was possible from the other, what was left was for me to try to validate myself. But, often, I submitted to my shame. It is not just about how we evaluate the self in the mind of the other, but also which emotions are connected and directed at the self that is grounds for shame (Cooley 1902) and then also for the possibility of a restoration of shame. To validate the self and restore oneself to a different mindset in relation to the other means being able to regulate one's self and emotions. Self-injury has to do with self-control (Brossard 2018) and coping (Adler and Adler 2011). Experiencing intense emotions of shame made me feel out of control and I needed something to "get myself together." Because shame did not easily lessen or disappear through more socially acceptable self-soothing practices. In fact, most of the time it did not work, as described by other self-injurers (see, e.g., autobiographies by Kettlewell 1999; Smith 2006).

In the next example, I continue to judge myself harshly. I see myself as driving my partner away, 
and I am certain that he cannot possibly respect me and love me. I retreat into my shame-wanting to go away. Here, we again talk over the telephone, and I write that I cannot endure how I think he sees me; his voice is filled with contempt and his eyes I imagine as being full of "disgust and frustration."

\section{Example 5}

Again, I became the pain in the ass, the one who does not understand. I am so ashamed because how can you continue to respect and love me now? Why do I drive you away? God, what is wrong with me? Take me away please, from the world, from my reality. My reality is a hell, my personal ocean, inextricably debased. What am I doing to myself, with us? You. You cannot be my love. You cannot save me, no one can. Not as you think.

You hang up the telephone. Silence and emptiness. I cannot love you like this. I believe I walk and walk, forward and forward, because I want to strive for life, a meaning, and a goal, but I don't get anywhere. In the end, I don't know who I am, more than lonely, empty, back to where I came from. I cannot find a way out; to continue loving you and allow you to love me back. I cannot hear you talk about me the way you do, to me, and I cannot see the disgust and the frustration in your eyes. Even if it is unintentional. I cannot stand the thought that, in certain moments, you cannot endure the person I am. [The diary, Monday, January 16, 2006, p. 53]

The diary example above is what happened when my partner was unable to validate me or justify my actions. When shame cannot be restored through the other or between two people in a relationship, it is then that we need to validate and make justifications for ourselves. However, when the workings of shame take control over you and your emotions in the way that it did for me, there is not much left that may provide relief. Then, you are way too deep in the feelings of shame and self-hate to calm yourself down. It was then and there that self-injury worked as my salvation; it could temporarily recondition me, allowing me to continue with my everyday life (Kettlewell 1999; Gunnarsson 2020). Self-injury makes it possible for an individual to control the self and the painful emotions that result from experiences of threatened social bonds. By controlling myself, I could again continue to meet social and cultural expectations and reconnect with others and with "society" (Gunnarsson 2020). However, since self-injury is considered a pathological behavior and a deviant practice, self-injury as a means of control and coping becomes yet another source of possible shame and stigma. Although self-injury was used to mitigate my shame, I can also be judged by others for engaging in such practice. Thus, shame and self-injury may turn into a self-perpetuating cycle of shame and self-injury (Gunnarsson 2020).

In the next diary excerpt, the actual decision to cut makes me calm, and I am decisive in what I am about to do, although there was often some hesitation involved. When I see the wide gap and the blood, calmness enters my body, like a relief. It is "a promise of peace and life." Why a promise of life? Because as the excerpt below shows, I can go on without all that despair and panic, and continue with my life, go to bed, and fall asleep. In that sense, the cutting becomes a way to validate and restore myself, when the other cannot or does not want to. The cutting always, more or less, worked. Sometimes, deeper cuts were necessary, but "the blood needs to come" and "there is no turning back" once I had pressed the razorblade against the skin. 


\section{Example 6}

The blood needs to come. I lock myself into the bathroom. I press the razorblade against my left arm. When I have decided to cut, it gives me a calm, but also an excitement that takes away the anxiety and the despair I might have felt earlier. Unfortunately, when one has come to where I was at, with the razorblade pressed against the arm, in hesitation, in fear (the heart is pounding and the pulse is beating), and when a drop of blood presses through and slowly drips down the arm, there is no turning back. What is running in our bodies, it cleanses us, nourishes us. Is it perhaps after all the solace of life I see, and not death as you think? The cutting, the blood, is a promise of peace and life. There and then. [The diary, Monday, January 16, 2006, p. 54]

The shame I felt was entranced in all I was and all I did. I felt I was the one responsible for what was going on in the relationship. I could not fathom his wrongdoings because when in love, you want to see the other as a good person (Jones 2012). One could feel shame for the other, but I always felt shame for who I was, especially in his eyes. As Cooley's (1902) idea of the looking glass self suggests, every word, gesture, facial expression, action, or implication from him provided some message to my self-worth. I often perceived messages from my partner as low self-worth, which generated and reproduced my deep shame. It could be a simple look on his face, of indignation; a gaze, which revealed that he did not find me trustworthy; or a sentence like "your arms look really horrible" (e.g., because of wounds and scars). When both of us ignored the shame I experienced, then I thought the hurt was coming from him (Retzinger 1995), even when this hurt was all in my mind. At times, I felt discredited (Goffman 1963), like a tainted and discounted person in his eyes, and this is what I also became to myself.
I needed the other, my partner, to rescue me from my harsh judgments that I thought came from him (Lewis 1971). When I was validated and I could feel acceptance from my partner, then the shame was lessened, and I could once again feel connected with him (Leeming and Boyle 2013). Often, I could not count on being validated by the other or having my justifying accounts honored. At such times, self-injury became a significant solution. I could punish myself, regulate my strong anxiety and other painful feelings stemming from shame, to uphold interactional (Brossard 2014) and social orders (Gunnarsson 2020). Emotions are significant for social order, as they are the social glue that holds us together. However, as shame is about disconnection or the mere threat of disconnection, self-injury becomes a way to restore the self and the self-other relationship, and hence to uphold social order, to get on with life and my various social and cultural commitments (Gunnarsson 2020). Arguably, the attacks on the body are a form of social control, as Mead (1934:255) puts it: “behavior controlled by self-criticism is essentially behavior controlled socially." It is not individual sadomasochism, as described in psychiatric literature and research (Favazza 2011); rather, it is an extreme form of self-criticism that is controlled socially.

The attacks on my body were not to destroy, but to uphold or salvage the relationship and the bond to the self and others (Gunnarsson 2020). By temporarily fending off shame by self-injury, I could calm myself down, without going haywire (Brossard 2018); moreover, I could get on with my life and reconnect with my partner. Self-injury becomes a form of social control (Brossard 2014), which the self enacts upon itself. By controlling the self-or in the words of other self-injuring 
individuals, by cutting the bad out of me (Harris 2000) - I may transform and be "good" again, and thus worthy of the gaze of the other, thus, mending the broken social bond that holds the shamedself trapped. Then again, as self-injury is a practice that can also be a source of more shame (Gunnarsson 2020), there is no easy way out of the intense feelings of shame.

\section{Concluding Remarks}

In this article, I have used accounts of my personal experiences to explore how shame is activated and restored in an intimate relationship, as well as what function self-injury has in the process. By writing myself into my work, I have tried to trace shame and shame reactions in my diary accounts and showed how the personal can be a means to writing the public (Church 1995). I argue that writing about myself can capture something of what it means to experience shame in a relationship and how shame can be managed by self-injury, which is as much about other people who self-injure as it is about me. Previously, shame has been found to be an unspoken emotion in self-injury and also used to escape, avoid, or fend of shame (McDermott et al. 2008: Gunnarsson 2020).

Shame and self-injury are taboo subjects (Scheff 2003; Steggals 2015). In shame, you want to hide, and the act of self-injury is mostly carried out alone and in secrecy. Still, both are very social phenomena. Shame is about whom I think I was in the eyes of the other (my partner), and self-injury is about what I sometimes did to manage this supposed perception from the other. The personal is such only on the surface because, in reality, we are all connected to one another. We are extremely aware of how others view us, and we culturally in-tune with the perceptions and attitudes of other people (Cooley 1902). In shame, we feel disconnected from the other; it is an emotional separation and injury to the self through insults, rejections, disapproval, unrequited love, betrayal, unresponsiveness, for example (Retzinger 1995). The diary entries show how hard I tried to reconnect with my partner; thus, my shame was also a signal that reminded me of the need to deal with our threatened bond (Scheff 2001). I dealt with it, at the time, to the best of my abilities, despite feeling alienated from him and myself, on a daily basis. As I could not adequately control myself in my relationship, I blamed myself, that is, I was the crazy one, sick, the broken one (see, e.g., Long 2018 on self-blame and self-injury). Self-injury was a way of achieving such control, at least temporarily. Although self-injury works temporarily to manage shame, in the long-term, it offers a similar shaky premise as being dependent on the other for the resolution of shame. As long as self-injury is comprehended foremost within a psychopathological discourse and not an intentional act of control and coping, individuals who self-injure will have to continue monitoring themselves for the reactions of others, thus, eliciting possibly more shame.

In the present moment of working with this study, I am no longer the same person I was before. I have changed, and although that change does not mean that I will never again use cutting to manage shame, it means that I am capable of acknowledging today when it is shame that I experience, and communicating it to others. I finally understand how shame works, and this has helped me to not get caught up in my emotions. So, although shame may take a hold of me at times, I am no longer, like before, controlled by my shame. 


\section{References}

Adler, Patricia A. and Peter Adler. 2011. The Tender Cut. Inside the Hidden World of Self-Injury. New York: NYU Press.

Anderson, Leon. 2006. "Analytic Autoethnography." Journal of Contemporary Ethnography 35(4):373-395.

Atkinson, Paul. 1997. "Narrative Turn or Blind Alley?” Qualitative Health Research 7:325-344.

Atkinson, Paul. 2006. "Rescuing Autoethnography." Journal of Contemporary Ethnography 35(4):400-404.

Bartky, Sandra Lee. 1990. Femininity and Domination. London: Routledge.

Brossard, Baptiste. 2014. "Fighting with Oneself to Maintain the Interaction Order: A Sociological Approach to Self-Injury Daily Process." Symbolic Interaction 37(4):558-575.

Brossard, Baptiste. 2018. Why Do We Hurt Ourselves? Understanding Self-Harm in Social Life. Indianapolis, Bloomington: Indiana University Press.

Church, Kathryn. 1995. Forbidden Narratives. Critical Autobiography as Social Science. London, New York: Routledge.

Cooley, Charles H. 1902. Human Nature and the Social Order. New York: Charles Scribner's Sons.

Denzin, Norman. K. 1983. "A Note on Emotionality, Self, and Interaction." American Journal of Sociology 89(2):402-409.

Ellis, Carolyn. 1991. “Sociological Introspection and Emotional Experience.” Symbolic Interaction 14(1):23-50.

Ellis, Carolyn, Tony. E. Adams, and Arthur P. Bochner. 2011. "Autoethnography: An Overview." Historical Social Research 36(4):273-290.

Favazza, Armando. 2011. Bodies under Siege. Self-Mutilation, Non-Suicidal Self-Injury, and Body Modification, $3^{\text {rd }}$ ed. Baltimore, MD: The Johns Hopkins University Press.

Fullagar, Simone. 2003. "Wasted Lives: The Social Dynamics of Shame and Youth Suicide." Journal of Sociology 39(3):291-307.

Gilbert, Paul et al. 2010. "Self-Harm in a Mixed Clinical Population: The Roles of Self-Criticism, Shame, and Social Rank." British Journal of Clinical Psychology 49:563-576.
Goffman, Erving. 1963. Stigma: Notes on the Management of Spoiled Identity. Englewood Cliffs, NJ: Prentice Hall.

Goffman, Erving. 1967. Interactional Ritual. Essays on Face-to-Face Behavior. New York: Pantheon Books.

Gunnarsson, Nina Veetnisha. 2020. "The Self-Perpetuating Cycle of Shame and Self-Injury." Humanity and Society. Retrieved February 17, 2021 (https://journals.sagepub.com/doi/ full/10.1177/0160597620904475).

Harris, Jennifer. 2000. "Self-Harm: Cutting the Bad Out of Me." Qualitative Health Research 10(2):164-173.

Hill, Kerry and Rudi Dallos. 2011. "Young People's Stories of SelfHarm: A Narrative Study." Clinical Child Psychology and Psychiatry 17(3):459-475.

Holt, Nicholas L. 2003. "Representation, Legitimation, and Autoethnography: An Autoethnographic Writing Story." International Journal of Qualitative Methods 2(1):18-28.

Hooks, Bell. 2000. All About Love. New Visions. New York: HarperCollins Publisher.

Huey, Laura, Danielle Hryniewicz, and Georgios Fthenos. 2014. "'I Had a Lot of Anger and That's What Kind of Led Me to Cutting Myself': Employing a Social Stress Framework to Explain Why Some Homeless Women Self-Injure." Health Sociology Review 23(2):148-158.

Ivanhoff, Andre, Marsha M. Linehan, and Milton Brown. 2001. “Dialectic Behavior Therapy for Impulsive Self-Injuries Behaviors." Pp. 149-173 in Self-Injurious Behaviors: Assessment and Treatment, edited by S. Daphne and E. Hollander. Washington, DC: American Press.

Jones, Ward E. 2012. "A Lover's Shame." Ethic Theory Moral Practice 15:615-630.

Kettlewell, Caroline. 1999. Skin Game. A Memoir. New York: St. Martin's Griffin.

Le Breton, David. 2018. “Understanding Skin-Cutting in Adolescence: Sacrificing a Part to Save a Whole." Body and Society. Special Issue: Skin Matters 24(1-2):33-54.

Leeming, Dawn and Mary Boyle. 2013. “Managing Shame. An Interpersonal Perspective." British Journal of Social Psychology 52(1):140-160. 
Lewis, Helen. 1971. Shame and Guilt in Neurosis. New York: IUP.

Long, Maggie. 2018. “'We're Not Monsters ... We're Just Really Sad Sometimes': Hidden Self-Injury, Stigma and Help-Seeking." Health Sociology Review 27(1):89-103.

Lundgren, David C. 2004. "Social Feedback and Self-Appraisals: Current Status of the Mead-Cooley Hypothesis." Symbolic Interaction 27(2):267-286.

Lynd, Helen M. 2013. On Shame and the Search for Identity. London: Routledge.

McDermott, Elisabeth, Katrina Roen, and Jonathan Scourfield. 2008. "Avoiding Shame: Young LGBT People, Homophobia and Self-Destructive Behaviors." Culture, Health and Sexuality 10(8):815-829.

Mead, George H. 1934. Mind, Self, and Society. Chicago: University of Chicago Press.

Mykhalovskiy, Eric. 1996. "Reconsidering Table Talk: Critical Thoughts on the Relationship between Sociology, Autobiography and Self-Indulgence." Qualitative Sociology 19(1):131-151.

Rao, (Rami) Rameshwari. 2006. "Wounding to Heal: The Role of the Body in Self-Cutting." Qualitative Research in Psychology 3(1):45-58.

Retzinger, Susanne M. 1991. "Shame, Anger and Conflict: Case Study of Emotional Violence." Journal of Family Violence 6(1):37-59.

Retzinger, Susanne M. 1995. “Identifying Shame and Anger in Discourse." American Behavioral Scientist 38(2):1104-1113.

Retzinger, Susanne M. 2002. "Alienation, Labeling, and Stigma: Integrating Social and Emotional Aspects of Mental Illness." Pp. 227-260 in Toward a Sociological Imagination: Bridging Specialized Fields, edited by P. Bernard, H. Kincaid, and T. J. Scheff. Lanham, MD: University Press of America.

Rier, David A. 2000. "The Missing Voice of the Critically Ill: A Medical Sociologist's First-Person Account." Sociology of Health E Illness 22(1):68-93.

Scheff, Thomas J. 2000. "Shame and the Social Bond: A Sociological Theory." Sociological Theory 18(1):84-99.

Scheff, Thomas J. 2001. "Shame and Community: Social Components in Depression." Psychiatry 64(3):212-224.

Scheff, Thomas J. 2003. "Shame in Self and Society." Symbolic Interaction 26(2):239-262.
Scheff, Thomas J. 2014. "The Ubiquity of Hidden Shame in Modernity." Cultural Sociology 8(2):129-141.

Scheff, Thomas J. and Susanne M. Retzinger. 2000. “Shame as the Master Emotion of Everyday Life." Retrieved August 25, 2015 (https://www.academia.edu/476112/Shame_as_the_master_emotion_of_everyday_life).

Schoenleber, Michelle, Howard Berenbaum, and Robert Motl. 2014. "Shame-Related Functions of and Motivation for Self-Injurious Behavior." Personality Disorders: Theory, Research, and Treatment 5(2):204-211.

Scott, Marvin B. and Lyman M. Stanford. 1968. "Accounts." American Sociology Review 33(1):46-62.

Seu, Bruna I. 2006. "Shameful Selves: Women's Feelings of Inadequacy and Constructed Façades." European Journal of Psychotherapy, Counselling and Health 8(3):285-303.

Smith, Carolyn. 2006. Cutting It Out: A Journey through Psychotherapy and Self-Harm. London: Jessica Kingsley Publishers.

Solomon, Yvette and Julie Farrand. 1996. “'Why Don't You Do It Properly?' Young Women Who Self-Injure." Journal of Adolescence 19:111-119.

Sparkes, Andrew C. 2000. "Autoethnography and Narrative of Self: Reflections on Criteria in Action." Sociology of Sport Journal 17:21-43.

Steggals, Peter. 2015. Making Sense of Self-Harm. The Cultural Meaning and Social Context of Non-Suicidal Self-Injury. New York: Palgrave Macmillan.

Turner, Jonathan. 2006. “Social Control and Emotions.” Symbolic Interaction 28(4):475-485.

Victor, Sarah Elisabeth and David E. Klonsky. 2014. "Daily Emotion in Non-Suicidal Self-Injury." Journal of Clinical Psychology 70(4):364-375.

Wall, Sarah Stahlke. 2016. "Toward a Moderate Autoethnography." International Journal of Qualitative Methods. Retrieved February 16, 2021 (https://journals.sagepub.com/doi/ full/10.1177/1609406916674966).

Xavier, Ann, José Pinto-Gouveia, and Marina Cunha. 2016. "Non-Suicidal Self-Injury in Adolescence: The Role of Shame, Self-Criticism and Fear of Self-Compassion." Child Youth Care Forum 45:571-586. 
The Activation and Restoration of Shame in an Intimate Relationship: A First-Hand Account of Self-Injury

\section{Citation}

Gunnarsson, Nina Veetnisha. 2021. "The Activation and Restoration of Shame in an Intimate Relationship: A First-Hand Account of Self-Injury." Qualitative Sociology Review 17(2):104-121. Retrieved Month, Year (http://www.qualitativesociologyreview. org/ENG/archive_eng.php). DOI: http://dx.doi.org/10.18778/1733-8077.17.2.06 